\title{
A EVOLUÇÃo DA LINGUAGEM NA ESPÉCIE HUMANA FRENTE A UMA DISCUSSÃO ANTROPOLÓGICA
}

\section{ARTIGO ORIGINAL}

ABRUNHOSA, Juremir Costa ${ }^{1}$

ABRUNHOSA, Juremir Costa. A evolução da linguagem na espécie humana frente a uma discussão antropológica. Revista Científica Multidisciplinar Núcleo do Conhecimento. Ano 05, Ed. 08, Vol. 10, pp. 118-124. Agosto de 2020. ISSN: 24480959, Link de acesso: https://www.nucleodoconhecimento.com.br/letras/discussaoantropologica

\section{RESUMO}

A sugestão original deste artigo é construir o processo evolutivo da linguagem humana a partir dos resultados antropológicos ao conhecimento da linguística, baseado em descobertas científicas e também como empreendimento gerador de reflexão aos paradigmas que envolvem os estudos contextuais que os grupos estão sujeitos. Sabemos que o surgimento da linguagem pode ter sido devido a um misterioso encontro (ainda desconhecido) de um determinado órgão da linguagem e as descobertas arqueológicas. No entanto, concluímos que este artigo navega na interseção entre o ambiente natural e as variáveis culturais e sociais fazendo uma transição da era evolucionária para a era histórica.

Palavras-chaves: Linguagem na espécie humana, evolução da linguagem, linguística, antropologia.

${ }^{1}$ Especialização em Antropologia - Universidade Cândido Mendes; Enfermagem e Obstetrícia - Universidade Gama Filho; Teologia - Universidade Metodista de São Paulo " cursando sexto período". 


\section{INTRODUÇÃO}

A proposta inicial deste ensaio é construir o processo de evolução da linguagem humana, a partir de resultados Antropológicos e Linguísticos, sem a pretensão da busca de resultados inéditos ou inovadores, e nem tão pouco a valorização dos inúmeros subprocessos do recorte, afim que não ocorra especificação exacerbada.

Para tanto, abordaremos uma visão baseada em algumas teorias sobre a evolução da linguagem na espécie humana, conforme a Linguística e a Antropologia moderna, bem como as Ciências Cognitivas em descrição da evolução da linguagem estabelecida durante a propagação do Homo sapiens na terra.

Nesse sentido, a existência da linguagem humana moderna está alicerçada em achados arqueológicos de uma cultura com níveis de complexidades, materiais, simbólicos e intelectuais, a cerca de 100000 anos. No entanto, essa habilidade extraordinária nos permite falar e se articula com outros módulos mentais, tais como a memória.

\section{A MÃE DE TODAS AS LÍNGUAS}

A partir de uma explicação tripartite por Berwick e Chomsky para uma arquitetura da linguagem, em que a primeira é composta por um sistema (i) sensório motor para a produção e a compreensão; também observamos (ii) um sistema que planeja e organiza o pensamento; e por último, (iii) é descrito como forma de representações estruturais, que possuem "interface" com os outros dois sistemas (i) e (ii), em (REBELLO; SOARES, 2018) alavancando-se como a coluna fundamental do tripé por que nos diferencia dos outros animais numa linguagem exposta com tamanho nível de diferenciação, afinal (KOTTAK, 2013, p.88) afirma que, "Somente os seres humanos falam. Nenhum outro animal tem qualquer coisa que se aproxime da complexidade da língua“.

Historicamente o Faraó Psamético, no Egito, organizou o primeiro laboratório, afim da identificação da origem das línguas, onde sua premissa seria que se duas crianças 
fossem afastadas de sua mãe, não se apropriariam da língua materna $e$ imediatamente falariam um idioma original, único e primeiro, conforme (DA REDAÇÃO, 1990 ).

Nesse sentido, a "(...) comparação entre as várias línguas do planeta, tanto as ainda faladas quanto as já desaparecidas, revela efetivamente algumas características comuns que apontam para a possível existência de uma língua primeira, mãe de todas" conforme (Op. Sic. ) Em sua produção acadêmica, Correlações entre evolução genética e evolução linguísticas estabelecidas durante à dispersão de Homo sapiens sobre à Terra, cita Cavalli-Sforza que, "À luz de novos dados arqueológicos, a concordância em relação à origem monogênica da linguagem verbal cresceu." (CHAPCHAP, 2012, p.09)

A religião nos (remonta) a uma Eva genética da linguagem, seja na história da Torre de Babel no universo judaico-cristão, seja na divisão das línguas e o percurso do caminho no mito chinês, como também na Pérsia com a mitologia de Arimã criando a diversidade cultural linguística, ou seja "Em $A$ interpretação das culturas Clifford Geertz vê a religião como a expressão da ordem cosmológica sublinhando e sustentando todos os outros aspectos da sociedade e da cultura, (...)" (LIMA, 2018, p.22). Portanto, o entendimento cultural em suas especificidades do que seja crença não está delimitado na área de abrangência das ciências da religião ou do sagrado. Entretanto, são objetos verificáveis pela Antropologia, e como fenômenos mentais pela psicologia resultando assim na materialidade do mundo. (CYRANKA, 2014, p. 168 ) cita Câmara, em que "[...] as línguas nascem de uma língua-mãe, das línguasramo nascem ramos menores e desses ramos menores surge uma bifurcação de dialetos. Finalmente, temos o tronco da árvore - a Ursprache, ou a protolíngua indogermânica."

A linguística histórico-comparativa em tentativa de reconstituição dos períodos não documentados, ligados a um grupo de línguas em percurso permitia integrar as correlações estabelecidas entre essas línguas pelo método histórico-comparativo num todo coerente, que explicava muitos aspectos de sua evolução e que autorizava, tendo em vista a coerência das correlações evolutivas, o parentesco demonstrado de tais 
línguas e sua origem comum (o indo-europeu), classificá-las como uma vasta família linguística indo-europeia, composta por mais de quarenta línguas. (PAIS, 1980) .

A Característica crucial do ser humano ter se desenvolvido numa linguagem com níveis significativos de complexidades, pode ter sido atribuída pelo fato de ser bípede e ter o desenvolvimento do cérebro após ao nascimento acarretando mecanismos que possibilitaram a fala e com inúmeras possibilidades de adaptação e isso tudo é Graças ao desenvolvimento fisiológico e anatômico que observamos a "(...) versatilidade para a resolução das mais variadas situações exigidas pela sobrevivência, num meio onde as inconstâncias e as variações são fatores relevantes." ( FERREIRA; SANTOS; SILVA; FARIA, 2000. p.190).

\section{A ARQUEOLOGIA DA FALA}

Num processo arqueológico a primeira etapa do planejamento é a colheita de dados, que possuem relevância de pensamentos e propósito humano, que vinculada a demarcação de área, de base escrita ou oral, posteriormente a investigação essencialmente em subsolo para a apropriação de artefatos e por último a análise em sitos arqueológicos, de modo a buscar entendimento sobre as transformações ocorridas, mudanças, impactos, diferenças e proximidades com a sociedade atual. Nesses sítios, existem indícios de ocupação humana no passado, e, a partir de uma pesquisa arqueológica, podem ser encontrados diversos materiais que denotam a vida de sociedades antepassadas, como: ossos humanos, artesanatos, cerâmicas, pedras, representações rupestres, restos de alimentos, entre outros, fala o arqueólogo Gordon Childe citado em (BARROSO, 2017)

A mais de 100000 anos identificamos humanoides que falavam, entretanto, ocorre vertentes científicas que acreditam, que no período Paleolítico, o homem de Neandertal, teve um surgimento aproximadamente a 300000 anos e exerciam comunicação tribal , obviamente, por exemplo em reuniões de acertos na obtenção e armazenamento de gorduras animais conseguidas na caça, como também na estocagem de comida, nos fazendo acreditar que possuíam habilidades cognitivas em níveis de especialização complexas. Lents (2015) afirma que na verdade, a maioria 
dos antropólogos concorda que o "grande avanço", que inaugurou a era moderna da existência humana, deveu-se aos avanços cognitivos finais que permitiram a linguagem complexa.

Um bebe aproximadamente de 4 meses já inicia modular a voz, assim que a laringe começa a se desenvolver, entretanto, o canal de fonação de um chimpanzé adulto pode emitir sons de todas as línguas conhecidas, mas não fala por que não por causa em não controlar este canal, assim entende (CARVALHO, 2019). Nesse sentido, a leitura de "Um espelho para a humanidade" nos explica sobre a comunicação de primatas não humanos. Nenhum outro animal tem qualquer coisa que se aproxime da complexidade da língua. Os sistemas de comunicação natural de outros primatas (macacos e símios) são os sistemas de chamamento, (KOTTAK, 2013), em que esses sistemas de linguagem falada consistem em um número limitado de sons (chamadas), que são produzidos apenas quando encontram certos estímulos ambientais.

A descoberta da linguagem articulada, se dá com achados em sítios arqueológicos do osso hioide que é a base da fonação, Indica a distância entra a faringe, laringe e a base do crânio, numa câmara em que sons podem ser articulados para a fala, possuindo uma relação direta com a mandíbula e foi encontrado numa espécie humana muito antiga,. "Com isso, os cientistas conseguiram concluir que o osso hioide era tão baixo na garganta dos neandertais quanto nos seres humanos modernos." (LENTS, 2015).

\section{CONCLUSÃO}

A linguagem numa (visão) histórico crítico é uma das variáveis no processo da evolução, com inúmeras evidências científicas biológicas, antropológicas e sociológicas, em seu objeto - a língua, que define a linguística com inúmeras roupagens, teorias e abordagens, em sua atividade constitutiva, evoluída em si, que atingiu uma dimensão significativa científica importante entre as ciências humanas, biológicas e sociais. 
Entendemos que o surgimento da linguagem pode ser devido ao encontro misterioso de um determinado órgão da linguagem (ainda desconhecido) e os achados arqueológicos. Entretanto, chegamos ao final do artigo com a interpretação, de que há uma interseção entre o ambiente natural e as variáveis culturais, fazendo-o passar da era evolutiva "darwiniana" para a histórica era "lamarckiana".

\section{REFERENCIAL}

BAGNO, Marcos. O que é Linguística ?, São Paulo, ano 2016. Disponível em $<\mathrm{h}$ ttps://www.parabolablog.com.br/index.php/blogs/o-que-e-linguistica> Acesso em: 05 de Mai. 2020.

BARROSO, Priscila Farfan. Antropologia e cultura / Priscila Farfan Barroso, Wilian Junior Bonete, Ronaldo Queiroz de Morais Queiroz; [revisão técnica: Guilherme Marin]. - Porto Alegre: SAGAH, 2017.

CARVALHO, Danniel da Silva; CERQUEIRA, Fernanda de Oliveira; MARIANO, Victor Cavalcanti. Biolinguística: da evolução da espécie à noção de parâmetros. Fórum Linguístico, Florianópolis, v. 14, n. 3, p. 2286-2299, set. 2017. ISSN 1984-8412. Disponível em: <https://periodicos.ufsc.br/index.php/forum/article/view/19848412.2017 v14n3p2286>. Acesso em: 14 maio 2020. doi:https://doi.org/10.5007/19848412.2017v 14n3p2286.

CARVALHO, Maurício. Evolução da Linguagem (Linguística). Youtube, 10 de dez. de 2019. Disponível em <https://www.youtube.com/watch?v=T1iyilGgp2I\&t=222s> .Acesso em: 05 de Mai 2020.

CYRANKA, Lucia F. Mendonça. Evolução dos estudos Linguísticos. UFJF.,2014. Disponível em <http://www.uff.br/praticasdelinguagem/files/2014/09/160-198 Evolu\%C3\%A7\%C3\%A3o-dos-estudos-lingu\%C3\%ADsticos.pdf>. Acesso em: 05 de Mai 2020.

CHAPCHAP, Gabriela Jubran. Correlações entre evolução genética e evolução linguística estabelecidas durante a dispersão de Homo sapiens sobre a Terra 
UNESP., 2012. Disponível em <https://repositorio.unesp.br/bitstream/handle/114 49/118653/chapchap_gj_tcc_rcla.pdf?sequence=1 > .Acesso em: 05 de Mai 2020.

FERREIRA, Roberto Godofredo Fabri et al . A filogênese da linguagem: novas abordagens de antigas questões. Arq. Neuro-Psiquiatr., São Paulo , v. 58, n. 1, p. 188194, Mar. 2000 . Available from <http://www.scielo.br/scielo.php?script=sci_artte xt\&pid=S0004-282X2000000100030\&lng=en\&nrm=iso $>$. access on 01 May 2020. htt ps://doi.org/10.1590/S0004-282X2000000100030.

FUNARI, Pedro Paulo Abreu. Lingüística e arqueologia. DELTA, São Paulo , v. 15, n. 1, p. 00, Feb. 1999 . Available from <http://www.scielo.br/scielo.php?script=sci_ arttext\&pid=S0102-44501999000100008\&Ing=en\&nrm=iso >. access on 05 May 2020. h ttp://dx.doi.org/10.1590/S0102-44501999000100008.

GONÇALVES, Renata R. F. A expressão do FOXP2: Uma introdução ao estudo das relações entre genes e linguagem. UFRGS,2006. Disponível em <https://www.lum e.ufrgs.br/bitstream/handle/10183/7722/000554769.pdf?sequence=1> .Acesso em: 05 de Mai 2020.

KOTTAK, Conrad Phillip Espelho para a humanidade [recurso eletrônico] : uma introdução concisa à antropologia cultural / Conrad Phillip Kottak ; tradução: Roberto Cataldo Costa ; revisão técnica: Carlos Caroso. - 8. ed. - Dados eletrônicos. - Porto Alegre : AMGH, 2013.

LENTS, NathanH , Did Neanderthals Speak?. The Human evolution blog , February 9, 2015. Disponível em <https://thehumanevolutionblog.com/2015/02/09/did-ne anderthals-speak/> .Acesso em: 05 de Mai 2020.

LIMA, Paulo Renato. Antropologia, Religião e Sociedade. Rio de Janeiro : UCAM INOVA EaD, 2018. Disponível em <http://portal.ead1.net/portal//ndex/lms>. acesso em 03 maio 2020.

PAIS, C. T. Algumas reflexões sobre os modelos em linguística. Língua e Literatura, São Paulo, n. 9, 1980. 
RASTIER, François. Tem a linguagem uma origem? Rev. bras. psicanálise, São Paulo, v. 43, n. 1, p. 105-117, mar. 2009 . Disponível em <http://pepsic.bvsalud.org/sci elo.php?script=sci_arttext\&pid=S0486-641X2009000100013\&lng=pt\&nrm=iso $>$. acesso em 03 mai 2020.

REBELLO, Rafaela; SOARES, Eduardo Correa. Resenha de Por que apenas nós? Linguagem e evolução. ReVEL, vol. 16, n. 31, 2018. [www.revel.inf.br]

REDAÇÃO, A busca pela mãe de todas as línguas. Abril, 31 maio 1990. Disponível em <https://super.abril.com.br/historia/antes-da-torre-de-babel/> .Acesso em: 05 de Mai 2020.

Enviado: Julho, 2020.

Aprovado: Agosto, 2020. 